\title{
The Difference of Superoxide Dismutase Levels in Patient's Saliva with Gingivitis Associated with Dental Plaque Only Before and After Scaling at Periodontics Installation, Faculty of Dentistry USU
}

\author{
Armia Syahputra \\ Department of Periodontology, Universitas Sumatera \\ Utara, Medan, Indonesia
}

\author{
Krisnamurthy Pasaribu \\ Department of Periodontology, \\ Universitas Sumatera Utara, Medan, Indonesia
}

\author{
Dina Pulungan \\ Student \\ Faculty of Dentistry, \\ Universitas Sumatera Utara, Medan, Indonesia
}

\begin{abstract}
Plaque induced gingival disease is the result of an interaction between the microorganisms found in the dental plaque biofilm and the tissues and inflammatory cells of the host. Polymorphonuclear leukocytes (PMN) are the first protection for tissues of the mouth and body. At the time of bacterial phagocytes, PMN leukocyte and macrophage cells produce reactive oxygen species (ROS). ROS will be issued on the tissue and can cause tissue damage through various mechanisms. ROS may cause oxidative stress, which is a condition an imbalance of ROS production and endogenous. Superoxide dismutase (SOD) is an endogenous antioxidant present in saliva counteracts against superoxide, SOD functions to catalyze the reaction dismutase of superoxide anion ROS into hydrogen peroxide and oxygen. Scaling therapy is the most commonly used procedure for treating gingivitis and periodontitis. Non-surgical therapy can restore and control both local and systemic antioxidant capacity such as modifying SOD levels and more. Previous studies have suggested superoxide dismutase levels in gingivitis patients higher after nonsurgical treatment, there are also studies suggesting higher levels of superoxide dismutase before nonsurgical treatment. This research is an experimental research with pre and posttest design. Was performed at the Periodontics Installation Faculty of Dentistry USU, with 12 subjects with gingivitis plaque induced only, the measurement of superoxide dismutase was performed twice before scaling and after scaling (PBI $<5) .2 \mathrm{ml}$ saliva was examined by spectrophotometry method and analyzed using $t$-paired test. The levels of superoxide dismutase in saliva before scaling $(13.59 \pm 4.59)$ higher than after scaling $(9.66 \pm 4.75)$, the difference was not significant $(p=$ $0.09, p>0.05)$. There was a difference in superoxide dismutase levels in saliva patients Gingivitis plaque induced only before and after scaling.
\end{abstract}

Keywords- superoxide dismutase, saliva, plaque- induced gingivitis, scaling (non-surgical treatment)

\section{INTRODUCTION}

Gingivitis occurs very commonly in all level of society; clinically gingivitis causes a reddened gingival margin, with pocket formation as a result of gingival swelling and edema, hypertrophy, and deepened penetration of periodontal probes on clinical evaluation [1]. The prevalence of gingivitis worldwide is $75-90 \%$ with moderate category reaching $75 \%$. Polymorphonuclear leukocytes (PMN) are a main protection of oral and body tissue [2]. PMN and macrophage will produce ROS when phagocyte bacteria. Reactive oxygen species will be excreted in the tissues and may cause periodontal tissue damage through various mechanisms $[2,3]$.

ROS is a highly reactive oxidant and has different activities. Negative impacts of these compounds arise from excessive activity and production of ROS, which can damage cell components that are critical in maintaining cell integrity [4]. Every ROS that is formed can start its activity thorough a chain reaction that continues until the ROS is eliminated by another ROS or antioxidant system. Reactive oxygen species can also cause oxidative stress that is responsible for most diseases [5].Oxidative stress is defined as an imbalance of production of ROS and endogenous antioxidants. Depletion of antioxidant causes breakdown in gingival ability to with stand oxidative stress, maintaining normal tissue condition, and controlling damage caused by bacteria [6].

SOD is an antioxidant enzyme that plays a role against superoxide, such us radical oxygen, which responsible for inflammatory process, which causes damage to connective tissue damage. SOD activity appears to be high in gingival, as a result of a higher demand for gingival protection in unhealthy periodontal compared to a healthy one [7]. Based on research 
results Kim et al. showed that the level of SOD in saliva decreased for 1 month and increased 3 months after of scaling and root planning treatment in patients with periodontal disease. This is because scaling can stimulate the gingival tissue. Proinflamatory factors are excreted when tissue is irritated, and SOD is secreted to balance of the effects of proinflamation [8]. Similarly, Yang et al. reported that the total antioxidant status and Superoxide dismutase decreased after scaling treatment [9].Wei et al. in his study also showed that superoxide dismutase levels in inflammation increased both locally and peripherally before non-surgical periodontal treatment and decreased after non-surgical treatment [10]. On the other hand study conducted by Kim et al showed the opposite results from study by Karim et al. which reported the SOD levels were higher in gingivitis compared with periodontitis before undertaking nonsurgical treatment and increased post-treatment of scaling and root planning 15 days in gingivitis patients around $51.2 \%$ in $53.6 \%$ periodontitis and in healthy periodontium $22.1 \%$ [11].

The purpose of this study is to look at the differences in the levels of superoxide dismutase in patients with plaque-induced gingivitis before and after scaling treatment.

\section{MATERIALS AND METHODS}

\section{A. Study population and clinical examination}

Subjects in this study were patients from the installation of Periodontics in the Faculty of Dentistry USU. Informed consent was obtained from those willing to participate in the study. The ethical permission for this study was obtained by the Ethics Committee on Health Research at the Faculty of Medicine, University of North Sumatra. The subject periodontal status is determined by examination of plaque index (Silness and Loe, 1964) [12], Gingiva Index (GI) (Loe and Silness, 1963) [13], and papillary bleeding index (PBI) (Saxer and Muhlemann, 1975) [13]. Subjects were categorized by gingival index score $>1$, probing depth $<4 \mathrm{~mm}$, and no attachment loss. Research subjects have a 20-55 year age range, have a permanent tooth of at least 20 teeth and are willing to be a research sample. Patients who were on antiinflammatory, smokers, pregnant and lactating woman, patients had no systemic disease, and those on dietary supplements were excluded from the study.

\section{B. Sampling of saliva}

Using the method of spitting and unstimulated saliva, saliva was immediately taken from the patient using saliva pot as much as $\pm 2 \mathrm{ml}$, after which patients receive care scaling and patients were instructed to maintain oral health hygiene. Saliva is recovered after scaling treatment with the provision of a PBI score $<5$. Saliva is brought to FK USU Laboratory using cooling box. Saliva is stored in the refrigerator $-80^{\circ} \mathrm{C}$.

\section{Analysis of SOD activity}

Collected saliva were transferred from collection tube to Eppendorf tube and centrifuged at $10000 \mathrm{rpm}$ for 60 seconds at $7^{\circ} \mathrm{C}$ before being analyzed. Salivary SOD levels were measured by EnzyChrom ${ }^{\mathrm{TM}}$ Superoxide Dismutase Assay Kit (ESOD-100) which included assay buffer $20 \mathrm{~mL}$, SOD enzyme $120 \mu \mathrm{L}$, Xanthine $600 \mu \mathrm{L}$, Diluent $20 \mathrm{~mL}$, XO enzyme $120 \mu \mathrm{L}$, and WST-1 $600 \mu \mathrm{L}$. Salivary SOD levels were measured using spectrophotometer. SOD enzyme $8 \mu \mathrm{L}$ were mixed with $392 \mu \mathrm{L}$ to give $3 \mathrm{U} / \mathrm{mL}$ SOD standard. Dilute standards as below.

TABLE I. DILUTE STANDARD SOD
\begin{tabular}{|c|c|c|}
\hline No. & $\mathbf{3 U} / \mathbf{m L}+$ Diluent & Standard $(\mathbf{U} / \mathbf{m L})$ \\
\hline 1 & $100 \mu \mathrm{L}+0 \mu \mathrm{L}$ & 3.0 \\
\hline 2 & $8-\mu \mathrm{L}+20 \mu \mathrm{L}$ & 2.4 \\
\hline 3 & $60 \mu \mathrm{L}+40 \mu \mathrm{L}$ & 1.8 \\
\hline 4 & $40 \mu \mathrm{L}+60 \mu \mathrm{L}$ & 1.2 \\
\hline 5 & $18 \mu \mathrm{L}+82 \mu \mathrm{L}$ & 0.54 \\
\hline 6 & $8 \mu \mathrm{L}+92 \mu \mathrm{L}$ & 0.24 \\
\hline 7 & $4 \mu \mathrm{L}+96 \mu \mathrm{L}$ & 0.12 \\
\hline 8 & $0 \mu \mathrm{L}+100 \mu \mathrm{L}$ & 0.0 \\
\hline
\end{tabular}

SOD standard $20 \mu \mathrm{L}$ were transferred to separate wells of a clear flat-bottom 96-well plate. Samples 20 $\mu \mathrm{L}$ were transferred to separate wells. The working reagent was prepared for the standard and sample wells. For each well, assay buffer $160 \mu \mathrm{L}$ were mixed with Xanthine $5 \mu \mathrm{L}$ and WST-1 $5 \mu \mathrm{L}$. The working reagent was transferred $160 \mu \mathrm{L}$ to each well and the plate was tapped to mix. For each well, the XO enzyme was diluted 1:20 in diluent. Quickly added $20 \mu \mathrm{L}$ diluted $\mathrm{XO}$ enzyme to each assay well (use of multi-channel pipettor). The plate was tapped to mix.

Immediately read $\mathrm{OD}_{400 \mathrm{~nm}}(\mathrm{OD} 420-460 \mathrm{~nm})\left(\mathrm{OD}_{0}\right)$. Standard and sample were incubated for 60 minutes at room temperature $25^{\circ} \mathrm{C}$, in the dark. After that, standard and sample were read OD440nm again $\left(\mathrm{OD}_{60}\right)$. For the calculation, each standard and sample well were calculated $\Delta \mathrm{OD}_{60}=\mathrm{OD}_{60}-\mathrm{OD}_{0}$. After that, calculated $\Delta \Delta \mathrm{OD}=\Delta \mathrm{OD}_{\mathrm{std} 8}-\Delta \mathrm{OD}$ for each standard and sample where $\Delta \mathrm{OD}_{\text {std } 8}$ is the $\Delta \mathrm{OD}$ for standard $\# 8$ (the standard with no SOD activity and highest possible absorbance). Plotted the standard curve $\Delta \Delta \mathrm{OD}$ vs. [SOD] (U/mL). The $\Delta \Delta \mathrm{OD}$ were used for sample to determine SOD activity of sample from the standard curve.

\section{Statistical analysis}

All measurements were recorded as the mean \pm standard deviation. Statistical analysis was performed using SPSS with t-paired test. 
III. RESULTS

TABLE II. DEMOGRAPHIC DATA OF PLAQUE-INDUCED ONLY GINGIVTIS SUBJECT

\begin{tabular}{|l|c|c|}
\hline \multirow{2}{*}{\multicolumn{1}{c|}{ Variable }} & Ningivitis plaque-induced only \\
\cline { 2 - 3 } & & N \\
\hline Gender & 3 & 25 \\
a. Male & 9 & 75 \\
b. Female & 10 & \\
\hline Aged & 2 & 83.4 \\
a. 18-35 years old & & 16.6 \\
b. 35-50 years old & 10 & 83.4 \\
\hline Regular teeth brushing & 2 & 16.6 \\
a. Yes & & \\
b. No & 0 & 0 \\
\hline Tooth-brushing Frequency : & 8 & 66.6 \\
a. 1 times/day & 4 & 33.4 \\
b. 2-3 times/day & & \\
c. >3 times/day & 1 & 8.33 \\
\hline Using mouthwash & 11 & 91.67 \\
a. Yes & & \\
b. No & 12 & 100 \\
\hline Bleeding when brushing teeth & 0 & 0 \\
a. Yes & & \\
b. No & 8 & 66.67 \\
\hline Classification of gingivitis & 4 & 33.33 \\
a. Mild & 0 & 0 \\
b. Moderate & & \\
c. Severe &
\end{tabular}

Table II shows that the subjects of the study were more women than men. As many as $83 \%$ of the study subjects had 18-35 years of age and $16.6 \%$ had age 35 50 years. Research subjects who brush regularly every day as much as $83.4 \%$ and irregular brushing as much as $16.6 \%$, with the frequency of brushing 2-3 times a day as much as $66.6 \%$ and as much as $33.4 \%$ brushing teeth more than 3 times a day. Total of $8.33 \%$ of subjects was used mouthwash after brushing, while $91.67 \%$ of subjects did not use mouthwash. The entire study subjects had bleeding on the gums when brushing their teeth. Total of $66.67 \%$ of the study subjects experienced mild gingivitis, $33.33 \%$ moderate gingivitis and no severe gingivitis.

TABLE III. NORMALITY TEST OF CLINICAL PARAMETERS OF GINGIVTIS PLAQUE-INDUCED ONLY SUBJECT BEFORE AND AFTER SCALING TREATMENT.

\begin{tabular}{|l|c|c|c|c|}
\hline \multicolumn{1}{|c|}{$\begin{array}{c}\text { Clinical } \\
\text { parameters }\end{array}$} & $\begin{array}{c}\text { Pre- } \\
\text { scaling }\end{array}$ & P & $\begin{array}{c}\text { Post- } \\
\text { scaling }\end{array}$ & P \\
\hline Plaque Index & 0.96 & 0.88 & 0.83 & 0.02 \\
\hline $\begin{array}{l}\text { Papillary Bleeding } \\
\text { Index }\end{array}$ & 0.92 & 0.36 & 0.68 & 0.01 \\
\hline Gingival Index & 0.93 & 0.54 & 0.59 & 0.00 \\
\hline
\end{tabular}

Based on Table III, the normality test showed that plaque index data, papillary bleeding index and gingival index were normally distributed ( $p>0.05$ ), so to test the difference of parameters before and after scaling by using T-Test (t-paired).

Based on Table IV statistical test can be seen the average plaque index, papillary bleeding index and gingival index on the subject of plaque induced gingivitis just before the scaling showed higher than average after scaling. The results of the difference data were statistically significant at $\mathrm{p}<0.05$.
TABLE IV. CLINICAL PARAMETERS OF GINGIVTIS PLAQUEINDUCED ONLY SUBJECT BEFORE AND AFTER SCALING TREATMENT.

\begin{tabular}{|l|c|c|c|}
\hline \multicolumn{1}{|c|}{$\begin{array}{c}\text { Clinical } \\
\text { parameters }\end{array}$} & \multicolumn{1}{|c|}{ Gingivitis plaque-induced only } & \multirow{2}{*}{ P } \\
\cline { 2 - 4 } & Pre-scaling & Post-scaling & \\
\hline Plaque Index & $0.49 \pm 0,18$ & $0.06 \pm 0,030$ & 0.000 \\
\hline $\begin{array}{l}\text { Papillary Bleeding } \\
\text { Index }\end{array}$ & $41.08 \pm 16,91$ & $3.83 \pm 0,71$ & 0.000 \\
\hline Gingival Index & $0.83 \pm 0,40$ & $0.16 \pm 0,21$ & 0.000 \\
\hline
\end{tabular}

TABLE V. NORMALITY TEST OF SOD LEVELS IN GINGIVITIS PLAQUE-INDUCED ONLY SUBJECT BEFORE AND AFTER SCALING TREATMENT.

\begin{tabular}{|c|c|c|c|c|}
\hline \multicolumn{5}{|c|}{ Levels of Superoxide dismutase } \\
\hline & Pre-scaling & $\mathbf{P}$ & Post-scaling & P \\
\hline Saliva & 0.92 & 0.34 & 0.98 & 0.99 \\
\hline
\end{tabular}

Based on Table $\mathrm{V}$ above normality test results, showed SOD levels in saliva of plaque induced gingivitis patients were normal distributed $(\mathrm{p}>0.05)$. So the test is continued by using paired t test.

TABEL VI. THE DIFFERENCE OF SOD LEVELS IN GINGIVITIS PLAQUE INDUCED ONLY PATIENT BEFORE AND AFTER SCALING TREATMENT.

\begin{tabular}{|l|c|c|}
\hline \multicolumn{3}{|c|}{ Level of Superoxide Dismutase } \\
\hline & SOD $($ Mean \pm SD) & P (sig) \\
\hline Pre-scaling & $13.59 \pm 4.59$ & \multirow{2}{*}{0.098} \\
\hline Post-scaling & $9.66 \pm 4.75$ & \\
\hline
\end{tabular}

$\mathrm{T}$ paired-Test, Significant $\mathrm{p}<0.05$

Table VI showed that the mean SOD content in the plaque-induced gingivitis-induced salivary subjects was higher than the mean after scaling, with $\mathrm{p}=0.098$, so $\mathrm{p}>0.05$, so that from the data obtained there was no significant difference statistically.

\section{DISCUSSION}

Several studies have compared the status of superoxide dismutase in the subjects of periodontal disease, including gingivitis as one of the common diseases commonly associated with non-surgical treatment. Karim et al. conducted a study measurement of superoxide dismutase and thiol antioxidant with samples taken from gingival sulcus and saliva sulcus samples on 24 subjects with gingivitis, 23 with periodontitis and 23 healthy controls. Karim's research carried out the measurements before the treatment of scaling and root planning and 15 days after treatment using spectrophotometric method. The results showed that superoxide dismutase levels increased after nonsurgical treatment and the difference in superoxide dismutase levels before and after treatment was insignificant [11]. Karim's results were inversely related to the study of Yang et al. who examined the effect of scaling on salivary antioxidant changes and oral health behaviors in the evaluation of periodontal treatment outcomes in which antioxidant superoxide dismutase was included. The results of Yang et al showed that superoxide dismutase levels were higher in subjects before scaling compared with after scaling treatment. But there is no significant difference [9]. 
The research results of Yang et al. are in accordance to a study by Wei et al. who in his study showed that superoxide dismutase levels in patients' saliva were higher in the group before periodontal therapy and decreased 16 weeks after treatment. However, there was no significant difference in levels of superoxide dismutase before and after periodontal therapy [10]. Later Novakovic et al. also found that the rate of superoxide dismutase in saliva was higher in the study subjects prior to non-surgical treatment. Novakovic conducted a study of salivary antioxidant status before and after non-surgical periodontal treatment [14].In this study, it was found that levels of superoxide dismutase in saliva of plaque-induced gingivitis patients before receiving scaling treatment was different after scaling, where superoxide dismutase levels were higher before scaling $(13.59 \pm 4.59)$ than after scaling $(9.66 \pm 4.75)$. However, the difference was not statistically significant $(p=0.09, p>0.05)$. The results also showed that there was significant difference between the mean plaque index, the gingival index and papillary bleeding index score before scaling with post-scaling. $(\mathrm{p}=0.00, \mathrm{p}$ $<0.05$ ), where the mean plaque index, gingival index, and papillary bleeding index score were higher in the subjects prior to scaling compared with cases after scaling. The results of this study indicate conformity with the Yang, Wei and Novakovic studies which suggest that superoxide dismutase levels in saliva are higher in the subjects with periodontal disease before scaling compared to after scaling. This is due to an antioxidant imbalance with free radicals (ROS) in the body, so that superoxide dismutase activity increases to neutralize it [14].

The results of this study contrasted with previous by Karim et al research, which says SOD levels rise 15 days after scaling and root planning treatment. Karim et al. said that the increase of superoxide dismutase after scaling and root planning treatment was due to the reduction of inflammation response resulting in a balance between ROS and antioxidants and lower superoxide dismutase levels prior to treatment due to persistent inflammation causing local antioxidants to decrease [11].

In contrast to Kim et al. the results of Kim's study are in accordance with Karim's research, however, Kim et al. research, explained that the superoxide dismutase levels of patients with periodontitis, gingivitis and control decreased for up to 1 month after scaling and root planning treatment which then increased again after 3 months post-treatment. This is because the scrolling can stimulate the gingival tissue. Proinflamatory factors are excreted when tissue is irritated by scaling and SOD is secreted to offset the effects of proinflamation [8].

Therefore, SOD activity on the subject before scaling, along with the development of inflammation. Antioxidants have an important role to the early development of bacterial colonization. Guarnieri et al. found, that the number of Polymorphonuclear leukocytes (PMN) increased highly in the gingival inflammatory region. They suspect that the production of O2- (free radicals) by PMN as a host response can cause damage if not balance of the concentrations of antioxidants [15]. PMN produces free radicals as a result of bacterial phagocytes along with macrophages, by generating reactive oxygen to eliminate anaerobic bacteria.

Increased levels of SOD activity in an inflammatory gingiva from a patient may indicate an increase in $\mathrm{O} 2$ which attack PMN in a disease situation. This increase in $\mathrm{O} 2$ production leads to oxidative stress, which ultimately results in an increased need for SOD production to establish the balance of ROS antioxidants to protect tissue [10]. Scaling therapy is the most commonly used procedure for treating gingivitis and periodontitis. During scaling, the inflamed gingival, tissue has a more severe inflammatory response. SOD is secreted to compensate for the increased inflammation $[8,9]$. This is probably why the SOD level in the subject before the scaling treatment is higher than the subject after scaling.

The results of this study were different from the previous research because of the data of various research subjects. Researchers did not limit the level of illness in the form of mild, moderate, and severe. The majority of subjects in this study experienced plaqueinduced gingivitis in the mild category. A researcher only use periodontal treatment in the form of scaling treatment, and then at the time of salivary sampling after scaling occurs the diversity of time of its taking. Other differences may occur because of the different method or inclusion and exclusion criteria used and other factors [16]. So the results obtained did not show statistically significant differences in data.

Periodontal disease is an important condition that must be controlled by medical personnel and the entire population. Antioxidant production can be improved in various ways such as regular exercise, good nutrition consumption, supplement [17]. Antioxidant substance can be obtained from vegetables and fruits includes vitamin $\mathrm{C}$, $\mathrm{E}, \quad \beta$-carotene, flavonoids, isoflavones, anthocyanins, catechins, and isokatekin and lipoic acid. These phytochemical compounds help protect cells from oxidative damage caused by free radicals [18].

Based on research results superoxide dismutase level in saliva of plaque induced gingivitis patient before and after scaling in Installation of Periodontics FKG USU concluded that there is a difference in superoxide dismutase levels in saliva of gingivitis plaque-induced only patients before and after scaling, superoxide dismutase levels in patients before scaling are higher than patients after scaling, and the difference in superoxide dismutase levels before and after scaling was not statistically significant $(\mathrm{P}>0.05)$.

\section{ACKNOWLEDGEMENTS}

The authors would like to extend their appreciation to those who helped in this research including all staff of Installation of Periodontics, Faculty of Dentistry 
USU and all staff of Laboratory at Medical Faculty of USU.

\section{REFERENCES}

[1] J.P. Fiorellini, P.G. Stathopolou, Clinical features of gingivitis. In: Carranza, Forrest, Jepsen, Klokkevold, Newman, Preshaw, Takei, Teughels, eds. Clinical periodontology, $12^{\text {th }}$ ed., St. Louis, Missouri: Elsevier Saunder, 2015: 45-46.

[2] G.M. Ardnt, P. Prishaw, B.S. Sybille, K. Gisela, G. Eike, "Lipid peroxidation and antioxidant activity in saliva of periodontitis patients: Effect of smoking and periodontal treatment," J. Clin. Oral Invest. Vol. 12, pp. 345-52, 2008.

[3] N.T. Phuong, P.T. Nghia, R.E. Marquis, "Zinc effect on oxidative physiology of oral bacteria," Adv. Nat. Sci., vol. 7(12), pp. 131-138, 2006.

[4] L. Maslachah, R. Sugihartuti, R. Kurniasanti, "Hambatan produksi reactive oxygen species radikal superoksida $(\mathrm{O} 2)$ oleh antioksidan vitamin E (A-Tocopherol) pada tikus putih (rattus norvegicus) yang menerima stressor renjatan listrik," Media Kedokteran Hewan, vol. 24, pp. 21-26, 2008.

[5] G. Kaur, N. Tirkey, V. Chanana, P. Pishi, K. Chopra, "Inhibition of oxidative stress and cytokine activity by curcumin in amelioration of endotoxin induce experimental hepatoxicity in rodents. J Clin. Exp. Immunol., vol. 145(2), pp. 313-321, 2006.

[6] R.G.S. Manjunath, "Role of antioxidants as an adjunct in periodontal therapy," Journal of Academy of Advanced Dental Research, vol. 2(2), pp. 9-16, 2011.

[7] F.A.Akalin, E. Baltaciogu, A. Alver, E. Karabulut, "Lipid peroxidation levels and total oxidant status in serum, saliva and gingival crevicular fluid in patients with chronic periodontitis," J. Clin. Periodontal, vol. 34, pp. 558-565, 2007.

[8] S.C. Kim, O.S. Kim, O.J. Kim, Y.J. Kim, H.J. Chung, "Antioxidant profile of whole saliva after scaling and root planning in periodontal disease," J. Periodontal Implant Sci., vol. 40, pp.167-168, 2010.

[9] P.S. Yang, W.C. Huang, S.Y. Chen, C.H. Chen, C.Y. Lee, C.T. Lin, Y.K. Huang, "Scaling stimulated salivary antioxidant changes and oral health behavior in an evaluation of periodontal treatment outcomes," Scientific World Journal, vol. 10, pp. 1-9, 2014.

[10] D. Wei, X.L. Zhang, Y.Z. Wang et.al., "Lipid peroxidation levels, total oxidant status and superoxide dismutase in serum, saliva and gingival crevicular fluid in chronic periodontitis patients before and after periodontal therapy," Australian Dental Journal, vol. 55, pp. 70-78, 2010.

[11] S. Karim, P.K. Pratibha, S. Kamath, U. Kamath, et al., "Superoxide dismutase and thiol antioxidant in gingival crevicular fluid and saliva," Dent. Res. J., vol. 3, pp. 266-272, 2012.

[12] Oral health database. (2017, February 18). Available: http://www.mah.se/CAPP/Methods-and-Indices/Oral-HygieneIndices/Silness-Loe-Index/.

[13] Gingival indices: state of art, gingival diseases-their aetiology, prevention and treatment. (2017, February 18). Available: http://www.intechopen.com/books/gingival-diseases-theiraetiology-prevention-and-treatment/gingival-indices-state-of-art.

[14] N. Novaković, S. Čakić, T. Todorović, B. Raičević, I. Dožić, V. Vanja Petrović, et al., "Antioxidative status of saliva before and after non-surgical treatment," vol. 141, pp. 163-168, 2011.

[15] P. Dahiya, R. Kamal, R. Gupta, R. Bhaerwaj, K. Chandhany, S. Kaur, "Reactive oxigen species in periodontitis," J. Indian Soc. Periodontal, vol. 17(4), pp. 411-416, 2013.

[16] M. Shirzaiy, S.M. Ansari, J.H. Dehghan, "Total anti-oxidant capacity of saliva on chronic periodontitis patients before and after periodontal treatment. J. Nepal Health Res. Counc., vol. 12(28), pp. 172-176, September 2014.

[17] E. Mojtaba, K. Davood, D. Hussein, 'Lower total antioxidant capacity in smokers compare to non-smokers," An International Journal, vol. 6(2), pp. 305-309, 2014.

[18] H. Winarsi, Antioksidan alami dan radikal bebas: Potensi dan aplikasinya dalam kesehatan. Yogyakarta: Kanisius, 2007, pp. 86-87. 